\title{
INTERVALOS DE CAPINAS NO CULTIVO ORGÂNICO DO ABACAXIZEIRO
}

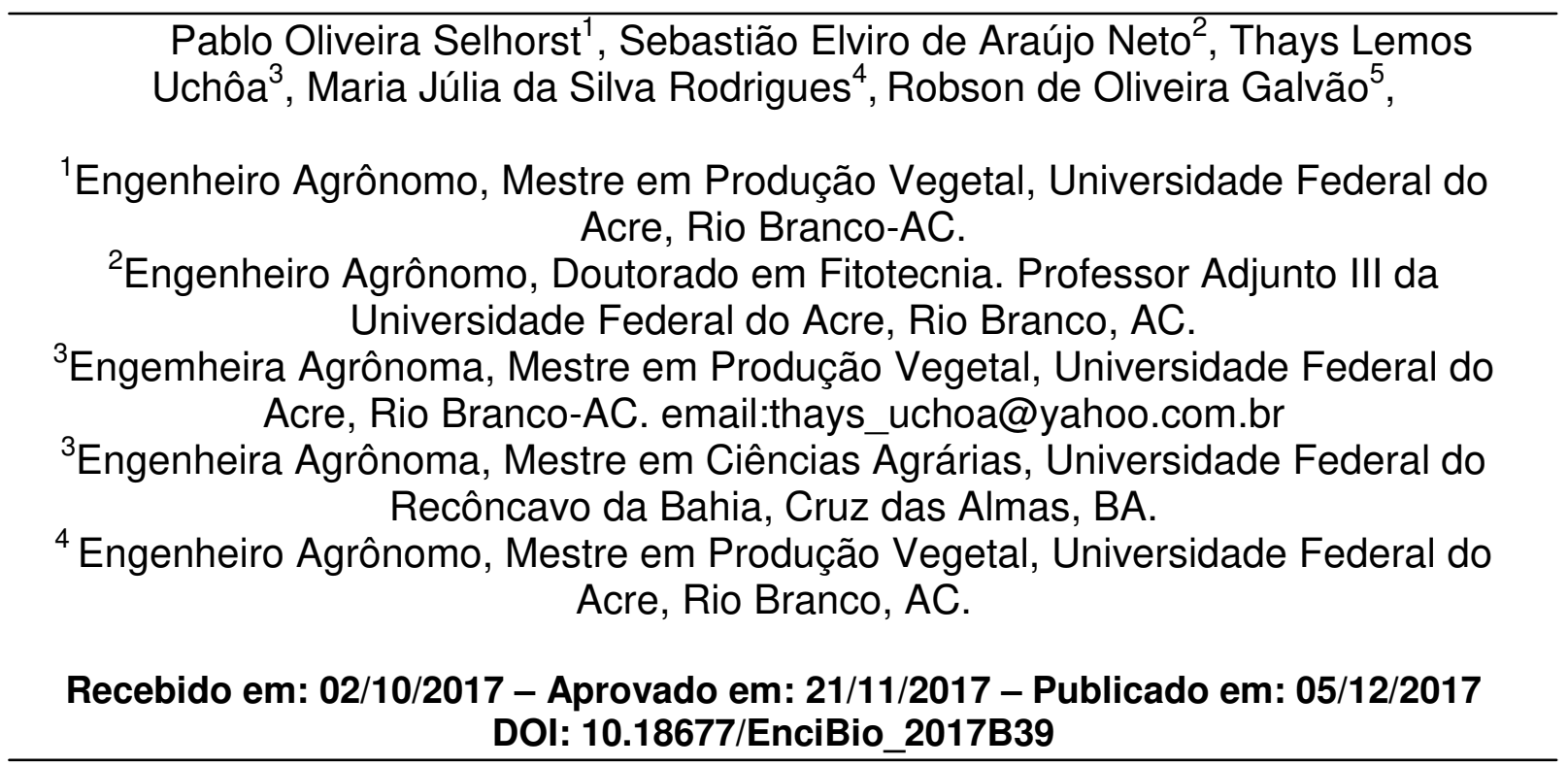

\section{RESUMO}

O abacaxizeiro (Ananas comosus (L.) Merril), é uma espécie adaptado ao Estado do Acre, porém apresenta baixa produtividade devido o baixo nível tecnológico empregado nas unidades produtivas. Os objetivos deste trabalho foram avaliar a produtividade do abacaxi orgânico cultivado com diferentes intervalos de capina, o custo da capina e a massa seca de plantas espontâneas. O experimento foi realizado em blocos casualizados simples com cinco tratamentos referentes aos intervalos de capinas: 30,60, 90, 120 e 150 dias após o plantio e quatro repetições. A parcela experimental média era composta por dezesseis abacaxizeiros $13,32 \mathrm{~m}^{2}$ $(3,60 \mathrm{~m} \times 3,70 \mathrm{~m})$. O abacaxi foi colhido e aferido sua massa com coroa e estimado a produtividade. Foram avaliadas as massas secas das plantas espontâneas, sendo coletadas de forma aleatória através do quadrado inventário, por corte rente ao solo, secadas em estufa até massa constante. O intervalo de capina que apresentou maior massa dos frutos e produtividade foi de 30 dias apresentando regressão linear decrescente até os 150 dias. O intervalo de capina de 30 dias apresentou maior custo. As plantas espontâneas apresentaram maior quantidade de massa seca no intervalo de capina de 150 dias durante o período de avaliação.

PALAVRAS-CHAVE: agricultura familiar, Ananas comosus, plantas espontâneas.

\section{INTERVALS OF WEEDING IN ORGANIC PINEAPPLE CULTIVATION}

\begin{abstract}
The pineapple (Ananas comosus (L.) Merril) is a species adapted to Acre state, but presents low productivity due to the low technological level employed in the farms. The objectives of this study were to evaluate the productivity of organic pineapple cultivated with different weeding intervals, the cost of weeding and the dry mass of spontaneous plants. The experiment was performed in a complete randomized


blocks with five treatments referring to the weed intervals: 30, 60, 90, 120 and 150 days after planting and four replications. The average experimental plot consisted of sixteen pineapples $13.32 \mathrm{~m}^{2}(3.60 \mathrm{~m} \times 3.70 \mathrm{~m})$. The pineapple harvested and measured its mass with crown and estimated productivity. The dry masses of the spontaneous plants was evaluated, being collected randomly through the square inventory, by cutting close to the soil and dried in a kiln until constant mass. The weeding interval presented the highest fruit mass and yield was 30 days, with a linear regression down to 150 days. The weeding interval of 30 days showed higher cost. Spontaneous plants had a greater amount of dry mass in the 150-day weed interval during the evaluation period.

KEYWORDS: Family farming, Ananas comosus, spontaneous plants.

\section{INTRODUÇÃO}

O abacaxizeiro (Ananas comosus (L.) Merril) nos últimos anos tem-se destacado pelo seu cultivo na maioria dos estados brasileiros, apresentando importância socioeconômica. No Brasil, a cultura é explorada principalmente pela agricultura familiar em áreas com até cinco hectares, geralmente, utilizando recursos próprios na sua implantação e manutenção (CUNHA et al., 2005).

As diferentes práticas agrícolas podem causar efeitos positivos ou negativos sobre os microrganismos e no teor de matéria orgânica do solo. Na agricultura agroecológica, a adição de adubos orgânicos como palhada, resulta no aumento da biomassa, melhorando o manejo de solo e água proporcionando melhoria nos rendimentos (HIRATA et al., 2014; ROSSET et al., 2014).

$\mathrm{Na}$ produção comercial, o abacaxizeiro requer tratos culturais frequentes, principalmente no manejo das plantas espontâneas nos primeiros seis meses após o plantio, pois o abacaxizeiro apresenta crescimento lento, favorecendo a competição por fatores de crescimento como água, luz e nutrientes (MATOS; SANCHES, 2011). Mesmo quando não há plantas espontâneas, encontra-se no solo banco de sementes aptas a germinar, com sua velocidade dependendo da sua abundância, época do ano, manejo do solo e cultura. Diante deste cenário, a capina é um importante manejo no controle dessas plantas (MODEL et al., 2006).

O intenso manejo e tratos culturais elevam os custos de produção, porém melhoram a qualidade dos frutos e consequentemente 0 valor comercial. $O$ aprimoramento nas técnicas de cultivo vem ao encontro do mercado consumidor exigente de qualidade e altamente competitivo. Segundo Araújo Neto et al. (2008) a tendência é que a agricultura orgânica seja mais viável economicamente devido à pouca demanda por insumos externos e produtividades constantes. No sistema orgânico, o custo de hortaliças orgânicas é de $8 \%$ menor quando comparado com convencional (SOUZA; GARCIA, 2013).

No Acre um dos principais problemas no cultivo do abacaxizeiro orgânico é o manejo das plantas espontâneas durante o período de alta precipitação pluviométrica, principalmente das espécies gramíneas. Outro aspecto importante é o intervalo de capinas ideal que proporcione maior eficiência no uso da mão de obra e o melhor desempenho produtivo da cultura. Diante disto, os objetivos deste trabalho foram avaliar a produtividade do abacaxi orgânico cultivado com diferentes intervalos de capina, o custo da capina e a massa seca de plantas espontâneas. 


\section{MATERIAL E MÉTODOS}

O experimento foi conduzido no Sítio Ecológico Seridó, em Rio Branco - Acre, situado na latitude 9 53'16" S e longitude de 67049'11' W, a uma altitude de $170 \mathrm{~m}$, no período de março de 2014 a dezembro de 2015. O clima da região é quente e úmido, do tipo Am, conforme a classificação de Köppen, com temperaturas médias anuais em torno de $24,5{ }^{\circ} \mathrm{C}$, umidade relativa do ar de $84 \%$ e a precipitação anual entre 1.700 a $2.400 \mathrm{~mm}$ (INMET, 2015).

O local do experimento apresenta topografia suavemente ondulada, o solo do tipo ARGISSOLO AMARELO Alítico plíntico, sem erosão aparente e drenagem moderada. Os valores da análise de solo na camada de 0-20 $\mathrm{cm}$ de profundidade estão representados na (Tabela 1).

TABELA 1- Composição química da análise de solo

\begin{tabular}{|c|c|c|c|c|c|c|c|c|c|c|c|c|c|}
\hline \multirow{3}{*}{ Solo } & $\mathrm{pH}$ & $\mathrm{P} \mathrm{Fe}$ & $\mathrm{Cu}$ & $\mathrm{Mn}$ & $\mathrm{Zn}$ & B & $\mathrm{K}$ & $\mathrm{Ca}$ & $\mathrm{Mg}$ & $\mathrm{Al}$ & $\mathrm{H}$ & M.O & V\% \\
\hline & $\mathrm{H}_{2} \mathrm{O}$ & & $\cdots-1$ & $\mathrm{dm}^{-3}$ & & & & $-m$ & olc $d$ & $n^{-3}$ & - & $\mathrm{gdm}$ & $\%$ \\
\hline & 5,4 & 2530 & 1,6 & 99 & 2,6 & 0,17 & 1,1 & 24 & 11 & 1 & 37 & 29 & 48,7 \\
\hline
\end{tabular}

A área utilizada do experimento foi de $213,12 \mathrm{~m}^{2}$, a qual inicialmente estava ocupada por plantas espontâneas como: alecrim (Alternanthera tenella), algodãozinho (Acalypha communis), amendoim bravo (Euphorbia heterophylla), barba de bode (Aristida longiseta), beiço de boi (Desmodium adscendens), betônica (Stachys officinale), braquiarinha (Brachiaria decumbens), braquiarão (Brachiaria brizantha), capim estrela (Rynchospora speciosa), capim Jaraguá (Hyparrhenia rufa), carrapicho (Cenchrus echinatus L.), caruru (Amaranthus deflexus), cheirosa (Hyptis lophanta), corda de viola (Ipomoea grandifolia), couve cravinho (Porophyllum ruderale), curraleira (Croton lundianos), erva andorinha (Chamaesyce hyssopifolia), goiabeira (Psidium guajava), grama de pasto (Paspalum notatum), guanxuma branca (Sida glaziovii), joá (Solanum viarum), junquinho (Cyperus surinamensis), língua de vaca (Symphytum officiale L.), lombrigueira (Spigelia anthelmia), malva (Sida cordifolia), malva roxa (Urena lobata), picão branco (Galinsoga parviflora), quebra pedra (Phyllantus niruri), serralha-mirim (Emilia sonchifolia), tiririca amarela (Cyperus esculentus), tirica do brejo (Cyperus difformis), tiriricão (Cyperus ferax), trapoeraba (Commelina benghalensis L.) e tiririca três quinas (Cyperus distans).

O abacaxizeiro foi plantado em março de 2014, utilizando-se mudas do tipo filhote, cultivar RBR-1 (Rio Branco). O sistema de plantio realizado foi direto, com auxílio de espeque, no espaçamento de $0,90 \mathrm{~m} \times 0,37 \mathrm{~m}$, correspondendo à densidade de 30.000 plantas ha ${ }^{-1}$. Não foi realizada adubação ou aplicação de defensivos químicos para controle de pragas e doenças.

$O$ delineamento experimental foi em blocos casualizados, com cinco tratamentos correspondendo aos intervalos de capina, sendo: 30; 60; 90; 120 e 150 dias e quatro repetições. A parcela foi composta por quatro linhas com dez plantas cada. As linhas externas eram as bordaduras e as internas tiveram como bordadura a primeira e a última planta de abacaxizeiro. Cada parcela teve área de 13,32 $\mathrm{m}^{2}$ (3,60 $\mathrm{m} \times 3,70 \mathrm{~m})$, sendo que a área útil foi composta por 16 plantas.

O abacaxizeiro foi plantado em 19/03/2014, com a cada 30 dias sendo feitas as capinas e coletas das plantas espontâneas referentes ao intervalo de capina. A identificação e quantificação das plantas espontâneas foram realizadas acompanhando os intervalos de capinas de 30,60, 90, 120 e 150 dias, até a indução floral. Foi utilizado o quadrado inventário de $0,50 \times 0,50 \mathrm{~m}$ e lançado de forma 
aleatória nas parcelas. As plantas espontâneas que se encontravam dentro do quadrado foram cortadas rente ao solo, identificadas por espécie, contabilizadas, colocadas em estufa de circulação de ar forçado a $60^{\circ} \mathrm{C}$ até massa constante e aferida as massas. Posteriormente, foram realizadas as análises estatísticas de massa seca conforme o intervalo de capina dos tratamentos e pelo somatório das massas por tratamento pelo período de 150 dias coletados.

Foram cronometradas as capinas por parcela para determinar o número de capinas, a quantidade de mão de obra em cada capina (homem dia ha ${ }^{-1}$ ) e o custo de mão de obra ( $\left.\mathrm{R} \$ \mathrm{ha}^{-1}\right)$ dos tratamentos no período do experimento. Foi avaliada a massa seca relativa (MSR) por meio da média da massa seca coletada em cada intervalo de capina. A massa seca acumulada (MSA) foi calculada por meio da somatória da massa seca colhida em cada época de capina.

O custo de mão de obra deu-se pela média dos tempos das parcelas, depois se utilizou-se a fórmula de cálculo da Diária $=\mathrm{T} \times(7 / 8)$, onde: $\mathrm{T}$ refere-se à média dos tempos de capina realizada por tratamento e $(7 / 8)$ devido à cronometragem ter sido feita de forma ininterrupta, sendo que (1/8) foi o tempo descontado para o trabalhador amolar a enxada, beber água e atender suas necessidades fisiológicas, depois este valor da parcela foi transformado em um hectare.

Para obter o valor do custo de mão obra foi feito a multiplicação do número de capinas, homem dia ha ${ }^{-1}$ e valor da diária estipulado em $\mathrm{R} \$ 50,00$ devido o preço de mercado na época do experimento. A implantação da cultura ocorreu no mês de alta precipitação pluviométrica, porém como no início do experimento não havia irrigação, o plantio passou os meses de junho, julho e agosto com precipitação baixa e irregular, fazendo com que as plantas sofressem com estresse hídrico e como consequência, o seu desenvolvimento foi retardado.

Após 15 meses de implantação da cultura do abacaxi, foi realizada a indução floral, utilizando $5 \mathrm{~mL}$ da solução de uréia $2 \%$ e Ethrel $0,15 \%$ na roseta floral das plantas através da bomba costal. As plantas foram irrigadas em 2015 com lâmina média de $6 \mathrm{~mm}^{\text {dia }}{ }^{-1}$ para que não sofressem nos meses com menor precipitação pluviométrica e por longos veranicos.

Após seis meses da indução floral (dezembro), os frutos com a coroa foram coletados e pesados em balança. Avaliou-se a massa através de 10 frutos por parcela, obtendo valores $\mathrm{em} \mathrm{kg} \mathrm{ha}^{-1}$. A produtividade foi avaliada multiplicando a massa dos frutos pela densidade de plantas distribuídas em um hectare, também obtendo valores em $\mathrm{kg} \mathrm{ha}^{-1}$.

Os dados foram submetidos à verificação dos outliers pelo teste Grubbs, aos pressupostos da análise de variância, normalidade dos resíduos pelo teste de Shapiro e Wilk e homogeneidade das variâncias pelo teste de Barttlet. Posteriormente, os dados foram submetidos à análise de variância a 1\%, identificada diferença significativa pelo teste $\mathrm{F}$ e aplicadas às análises de regressão.

\section{RESULTADOS E DISCUSSÃO}

Os períodos de capinas utilizados na vegetação espontânea interferiram na massa média e na produtividade dos frutos (Figura 1 e 2). A massa média dos frutos foi influenciada pelo intervalo de capina, respondendo em função linear, com redução de $3,1 \mathrm{~g}$ de fruto para cada intervalo de capina (Figura 1 ).

A redução da massa média dos frutos pode ter ocorrido pela competição com a vegetação espontânea, devido à eficiência dessas na absorção de nutrientes, associada a capacidade de infestação e de liberação de aleloquímicos na cultura 
principal (FIALHO et al., 2012). Conforme Cunha et al. (1999) infestações com tiririca (Cyperus rotundus) e capim-colchão (Digitaria horizontalis), reduz significativamente os teores de N, P, $\mathrm{K}$ e Ca na folha e fisiologicamente.

A presença da vegetação espontânea constante no solo pode prevenir a erosão, proteger da chuva e radiação direta, menor densidade do solo, equilíbrio ecológico e serve de refúgio de predadores (SOUZA et al., 2012), a competição com a cultura comercial por mais de 60 dias, causa perda em relação à massa dos frutos. A planta passa $1 / 3$ de sua biomassa para o fruto, por isso, plantas em competição, possuem menor biomassa e produziram frutos pequenos.

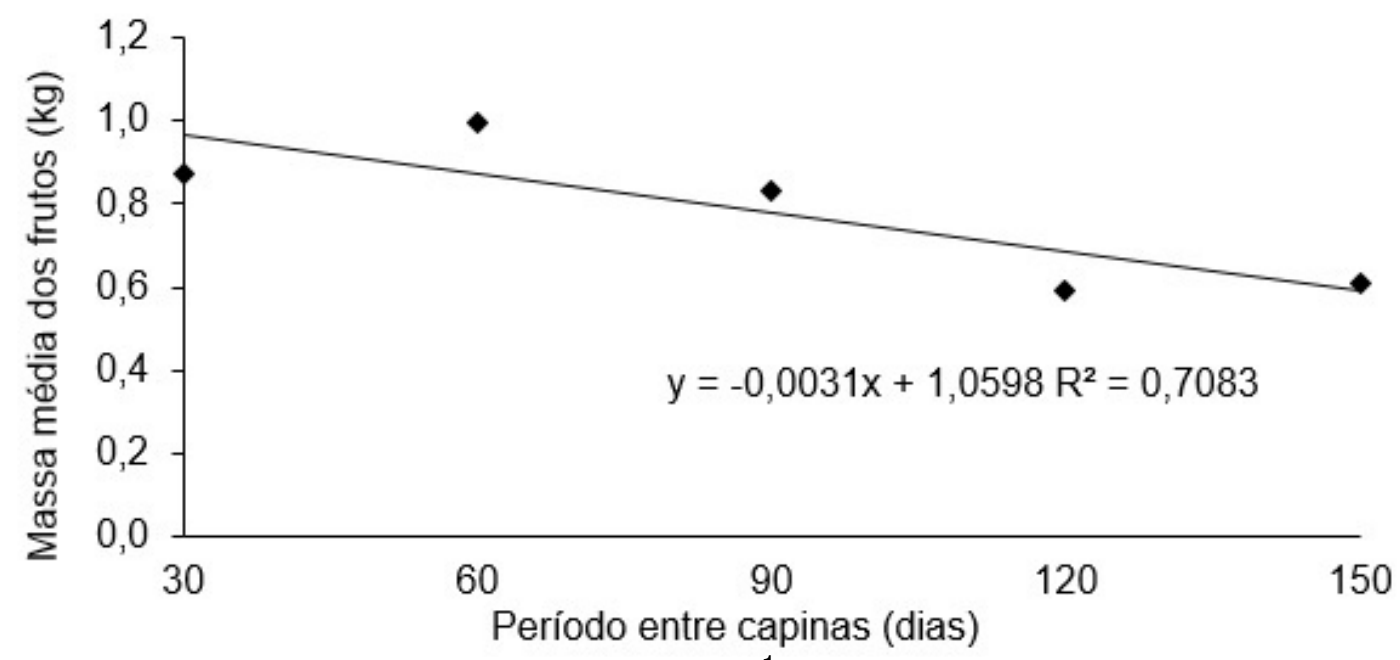

FIGURA 1- Massa média do abacaxi $\left(\mathrm{kg}_{\text {fruto }}{ }^{-1}\right)$ em sistema orgânico, cultivado com diferentes intervalos de capina, Sítio Ecológico Seridó, Rio Branco - Acre, 2015.

No Brasil há uma demanda de frutos maiores, porém o mercado internacional é favorável aos produtos menores de origem agroecológica, tendo exigência por frutos com massa entre 0,5 e $1,0 \mathrm{~kg}$ (PÁDUA et al., 2016) sendo que nos intervalos de capina de 30, 60 e 90 dias apresentaram massas médias entre 780,8 a 966,8 g. A produtividade do abacaxizeiro respondeu em função linear aos intervalos de capina com redução de 93,3 $\mathrm{kg} \mathrm{ha}^{-1}$ para cada dia de intervalo de capina (Figura 2).

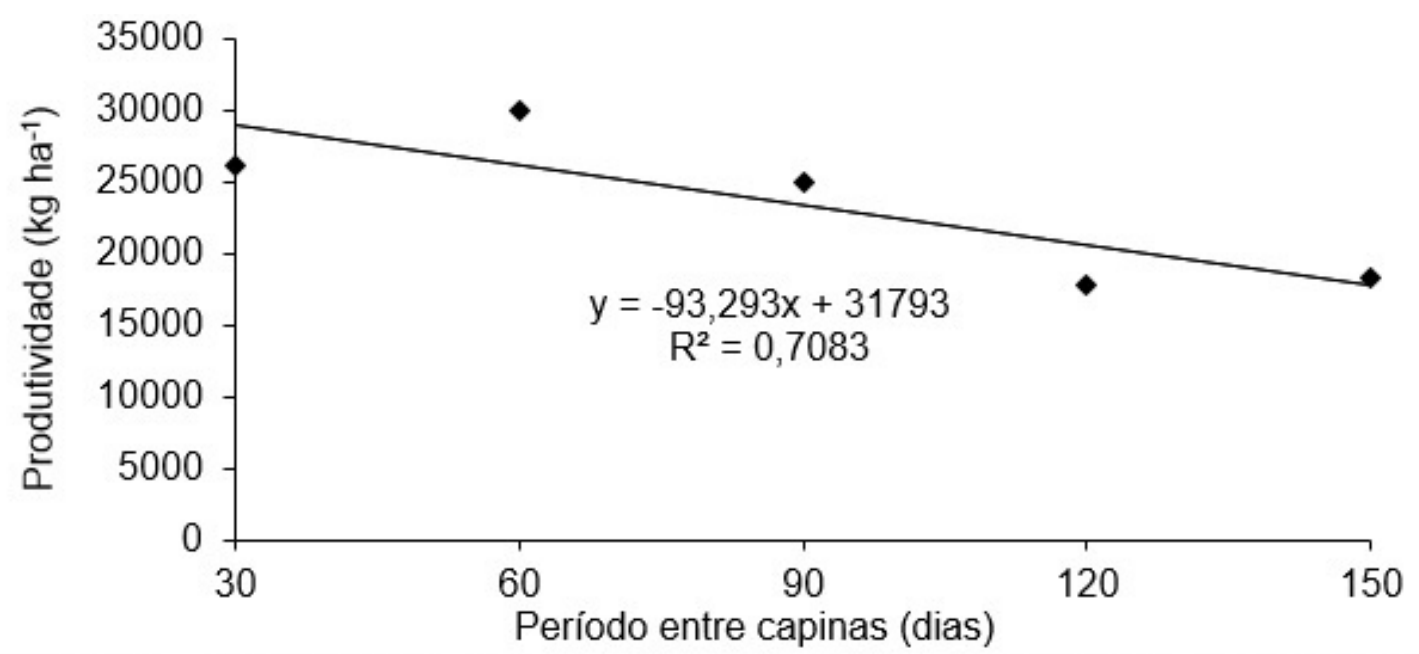

FIGURA 2 - Produtividade $\left(\mathrm{kg} \mathrm{ha}^{-1}\right)$ do abacaxizeiro nos intervalos de capina em experimento realizada no Sítio Ecológico Seridó, Rio Branco - Acre, 2015. 
A redução pode ter ocorrido pela maior competição por água, luz e nutrientes com as plantas espontâneas (GALVÃO et al., 2013; JUNIOR; MARTINS, 2014). O abacaxizeiro tem porte baixo e desenvolvimento vegetativo inicial lento, por isso, a concorrência é maior nos seis primeiros meses após o plantio, podendo interferir no estabelecimento da muda e posteriormente na produção e qualidade dos frutos (REINHARDT, 2002).

Quando se utilizou menor intervalo entre capinas, foram obtidos maiores rendimentos por unidade de área, contudo, elevou-se o custo de produção. A interferência competitiva das plantas espontâneas na cultura de valor comercial prejudica o desempenho da lavoura, portanto cultivos de abacaxizeiros capinados com maior frequência tendem a proporcionar produtividades elevadas (MATOS; SANCHES, 2011). Apesar do número de capinas ser elevado no intervalo de 30 dias (Tabela 2), a quantidade de dias para capinar um hectare é menor devido às plantas espontâneas ainda estarem pouco desenvolvidas, tornando mais fácil e rápido a operação.

TABELA 2 - Dados referentes ao intervalo entre capina, número de capinas, mão de obra em cada capina (homem dia ha ${ }^{-1}$ ), valor da diária $\left(R \$ d^{-1} a^{-1}\right)$ e custo da mão de obra $\left(R \$ h^{-1}\right)$, experimento realizado no Sítio Ecológico Seridó, Rio Branco - Acre, 2015.

\begin{tabular}{ccccc}
\hline $\begin{array}{c}\text { Intervalo entre } \\
\text { capinas }\end{array}$ & $\begin{array}{c}\text { Número de } \\
\text { capinas }\end{array}$ & $\begin{array}{c}\text { Mão de obra em } \\
\text { cada capina } \\
\left(\text { Homem dia ha }^{-1}\right)\end{array}$ & $\begin{array}{c}\text { Valor da diária } \\
\left(\mathrm{R} \$ \text { dia }^{-1}\right)\end{array}$ & $\begin{array}{c}\text { Custo com mão } \\
\text { de obra }\left(\mathrm{R} \$ \text { ha}^{-1}\right)\end{array}$ \\
\hline 30 & 21 & 5,49 & $\mathrm{R} \$ 50,00$ & $\mathrm{R} \$ 5.764,50$ \\
60 & 10 & 8,56 & $\mathrm{R} \$ 50,00$ & $\mathrm{R} \$ 4.280,00$ \\
90 & 7 & 9,97 & $\mathrm{R} \$ 50,00$ & $\mathrm{R} \$ 3.489,50$ \\
120 & 5 & 10,51 & $\mathrm{R} \$ 50,00$ & $\mathrm{R} \$ 2.627,50$ \\
150 & 4 & 10,65 & $\mathrm{R} \$ 50,00$ & $\mathrm{R} \$ 2.130,00$ \\
\hline
\end{tabular}

Nota-se que a produtividade é compensada pelo custo de mão de obra, fato observado por Araújo Neto et al. (2008) em cultivo orgânico. Model e Fraveto (2010) também trabalhando com abacaxizeiro obtiveram resultados mais onerosos, pois foram necessárias 15 diárias para capinar um hectare no intervalo de 60 dias. Contudo, no presente trabalho foram necessárias apenas 8,56 diárias.

Não foi observada diferença significativa na massa seca acumulada das plantas espontâneas (Figura 3). A massa média por capina das plantas espontâneas respondeu em função linear, com aumento de $29,445 \mathrm{~kg} \mathrm{ha}^{-1}$ para cada dia de intervalos de capina, atingindo $4.328,81 \mathrm{~kg} \mathrm{ha}^{-1}$ no intervalo de 150 dias (Figura 3). Este aumento pode ter ocorrido devido seu estádio de desenvolvimento e/ou estar correlacionadas com a capacidade competitiva das plantas espontâneas (REINHARDT, 2002).

O período que mais proporcionou massa seca de plantas espontâneas foi no intervalo de 150 dias, resultando em 4.328,81 $\mathrm{kg} \mathrm{ha}^{-1}$, provavelmente ocasionado pela maior competição por água, luz e nutrientes. Com isso, Reinhardt, (2002) afirma 
que a cultura do abacaxizeiro sofre grande concorrência devido ao seu baixo porte e desenvolvimento lento.

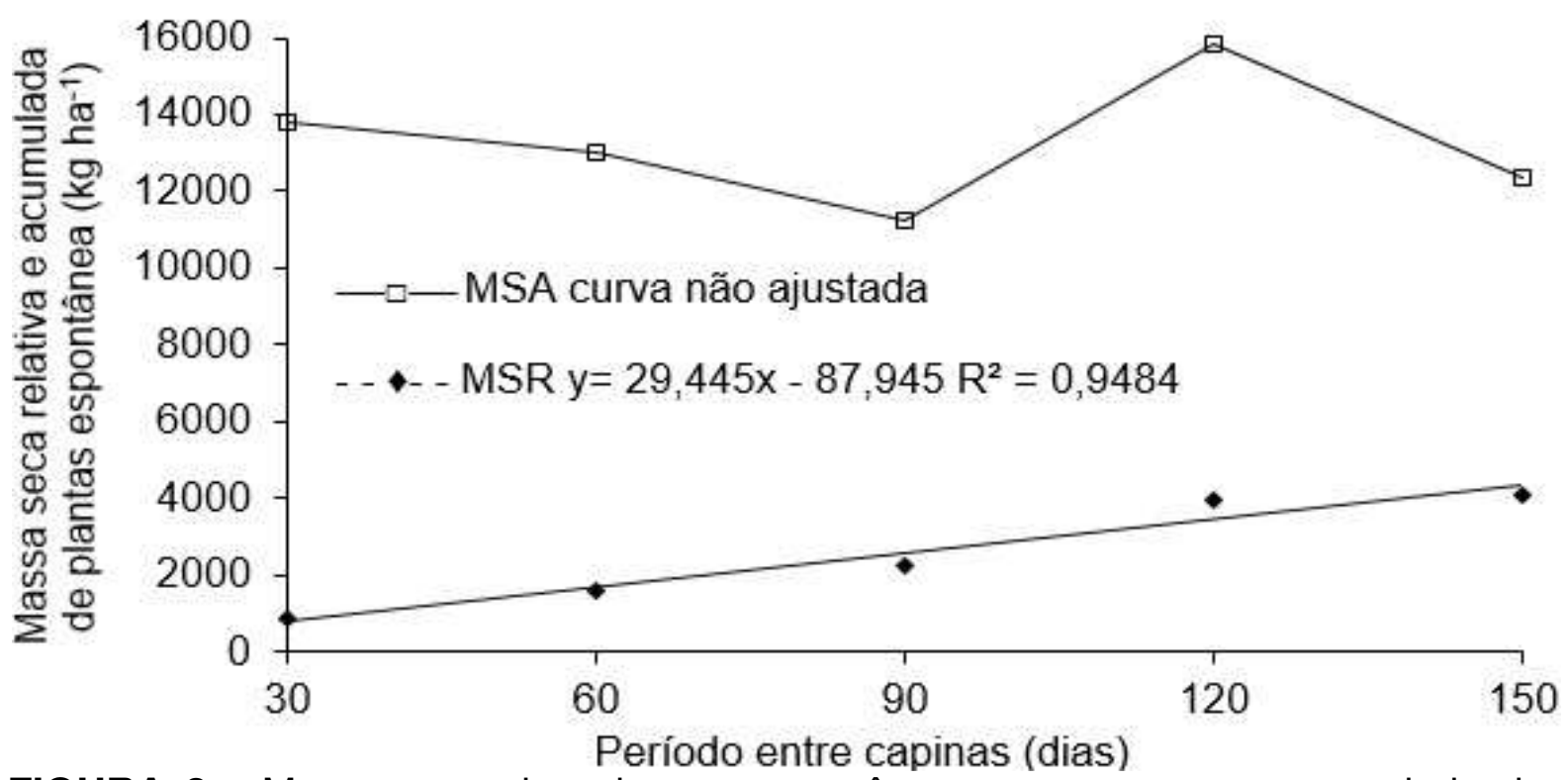

FIGURA 3 - Massa seca das plantas espontâneas e massa seca acumulada das plantas espontâneas $\left(\mathrm{kg} \mathrm{ha}^{-1}\right)$ nos intervalos de capina em experimento realizado no Sítio Ecológico Seridó, Rio Branco - Acre, 2015.

O intervalo de capina de 30 dias (Figura 3) apresentou a menor quantidade de massa seca de plantas espontâneas, com 795,41 $\mathrm{kg} \mathrm{ha}^{-1}$, possivelmente devido ao curto intervalo de capina, fazendo com que a vegetação espontânea tenha menos tempo para se desenvolver. A maioria das plantas espontâneas apresenta baixa capacidade produtiva, porém é importante o seu manejo, pois contribui na fertilidade do solo, aumenta a capacidade retenção do solo, reduz a erosão e danos às plantas de valor comercial (GALVÃO et al., 2013).

\section{CONCLUSÃO}

A produtividade dos frutos e o custo da mão-de-obra diminuem com maiores intervalos de capina, enquanto a biomassa seca das plantas espontâneas aumenta a cada intervalo, embora o acumulo de biomassa seca no período seja o mesmo, tornando mais eficiente economicamente e menos penoso intervalos entre 30 a 90 dias.

\section{REFERÊNCIAS}

ARAÚJO NETO, S. E. de; FERREIRA, R. L. F.; PONTES, F. S. T.; NEGREIROS, J. $R$. da S. Rentabilidade econômica do maracujazeiro-amarelo plantado em covas e em plantio direto sob manejo orgânico. Revista Brasileira de Fruticultura, v. 30, n. 4, p. 940-945, 2008. Disponível em: < http://dx.doi.org/10.1590/S0100-29452008000 400017>. Doi: 10.1590/S0100-29452008000400017.

CUNHA, G. A. P.; CABRAL, J. R. S.; SOUZA, L. F. S. O abacaxizeiro: cultivo, agroindústria e economia. Cruz das Almas: Embrapa Mandioca e Fruticultura, 1999. 480 p. (Embrapa Comunicação para Transferência de Tecnologia). 
CUNHA, G. A. P.; REINHARDT, D. H.; MATOS, A. P.; SOUZA, L. F. S.; SANCHES, N. F.; CABRAL, J. R. S.; ALMEIDA, O. A. Recomendações técnicas para o cultivo do abacaxizeiro. Cruz das Almas: Embrapa Mandioca e Fruticultura Tropical, 2005. (Circular técnica, 73).

FIALHO, C. M. T.; SILVA, A. A.; FARIA, A. T.; TORRES, L. G.; ROCHA, P. R. R.; SANTOS, J. B. Teor foliar de nutrientes em plantas daninhas e de café cultivadas em competição. Planta Daninha, v. 30, n. 1, p. 65-73, 2012. Disponível em: < http://dx.doi.org/10.1590/S0100-83582012000100008>. Doi: 10.1590/S010083582012000100008.

GALVÃO, R. O.; ARAÚJO NETO, S. E.; FERREIRA, R. L. F. Plantio direto orgânico de alface sobre cobertura viva e morta e adubada com composto. Agropecuária Científica no Semi-Árido, v. 9, p. 75-80, 2013.

HIRATA, A. C. S.; HIRATA, E. K.; GUIMARÃES, E. C.; RÓS, A. B.; MONQUERO, P. A. Plantio direto de alface americana sobre plantas de cobertura dessecadas ou roçadas. Bragantia, v. 73, n. 2, p. 178-183, 2014. Disponível em: < http://dx.doi.org/ 10.1590/brag.2014.024>. Doi: 10.1590/brag.2014.024.

INMET. Instituto Nacional de Meteorologia. Banco de dados meteorológicos para ensino e pesquisa. 2015. Disponível em: <http://www.inmet.gov.br/portal/ index.php? r=bdmep/bdmep>. Acesso em: 19 Jan. 2016.

JUNIOR, E. J. S.; MARTINS, A. B. G. ESTAQUIA EM ANONAS. Revista Brasileira de Fruticultura, v. 36, n. spe, p. 147-156, 2014. Disponível em: < http://dx.doi.org/10.1590/S0100-29452014000500018>. Doi: 10.1590/S010029452014000500018.

MATOS, A. P. de; SANCHES, N. F. Cultura do abacaxi: sistemas de produção para a região de Itaberaba, Bahia. Cruz das almas: Embrapa Mandioca e Fruticultura. 2011. 59 p. (Documentos 138).

MODEL, N. S; FAVRETO, R. Comparação de custos de tratamento de controle de plantas daninhas em abacaxizeiro cultivado no Rio Grande do Sul. Pesquisa Agropecuária Gaúcha, v. 16, n. 1, p. 45-50, 2010.

MODEL, N. S; FAVRETO, R.; RODRIGUES, A. E. C. Efeito do preparo de solo e de técnicas de plantio na composição botânica e biomassa de plantas daninhas no abacaxizeiro. Pesquisa Agropecuária Gaúcha, v. 12, n. 1-2, p. 57-64, 2006.

PÁDUA, T. R. de; MATOS, A. P. de; ROSA, R. C. C.; REIS, R. C.; VIANA, E. de S.; SASAKI, F. F. C. Plantio e densidade populacional para as cultivares de abacaxi Pérola e BRS Imperial em sistema orgânico de produção na região de Lençóis, Chapada Diamantina - BA. Cruz das Almas: Embrapa Mandioca e Fruticultura. 2016. 4 p. (Circular técnica 120).

REINHARDT, D. H.; CABRAL, J. R. S.; SOUZA, L. F. S.; SANCHES, N. F.; MATOS, A. P. Pérola and Smooth Cayenne pineapple cultivars in the state of Bahia, Brazil: 
growth, flowering, pests, diseases, yield and fruit quality aspects. Fruits, v. 57, p. 4353, 2002. Disponível em: https://doi.org/10.1051/fruits:2002005. Doi: 10.1051/fruits: 2002005.

ROSSET, J. S.; COELHO, G. F.; STREY, M. G. L.; GOLÇALVES JUNIOR, A. C. Agricultura convencional versus sistemas agroecológicos: modelos, impactos, avaliação da qualidade e perspectivas. Scientia Agraria Paranaensis, v. 13, n. 2, p. 80-94, 2014. Disponível em: < http://dx.doi.org/10.1818/sap.v13i2.7351>. Doi: 10.1818/sap.v13i2.7351.

SOUZA, J. L. de; GARCIA, R. D. C.; custos e rentabilidades na produção de hortaliças orgânicas e convencionais no estado do espírito santo. Revista Brasileira de Agropecuária Sustentável, v. 3, n. 1, p. 11-24, 2013.

SOUZA, J. L. de; PREZOTTI, L. C.; MARTINS, A. G. Potencial de sequestro de carbono em solos agrícolas sob manejo orgânico para redução da emissão de gases de efeito estufa. Idesia, v. 30, n. 1, p. 7-15, 2012. Disponível em: < http://dx.doi.org/ 10.4067/S0718-34292012000100002>. Doi: 10.4067/S0718-34292012000100002. 